\title{
Review
}

\section{Mucins and mucosal protection in the gastrointestinal tract: new prospects for mucins in the pathology of gastrointestinal disease}

The luminal surface of the gastrointestinal tract is covered by a viscoelastic mucous gel layer that acts as a protective barrier against the harsh luminal environment. The structural characteristics of this barrier are primary indicators of its physiological function and changes to its composition have long been identified in gastrointestinal pathologies. During the past decade significant improvements in analytical techniques coupled with detailed knowledge of the genes coding for the mucin proteins have provided exciting new insights into the role of the mucous layer and its relevance to gastrointestinal disease.

The high molecular weight mucins are responsible for the viscoelastic properties of the mucous barrier. They are widely expressed in epithelial tissues and are characterised by variable number tandem repeat peptide sequences rich in serine, threonine, and proline which carry large numbers of $O$-linked oligosaccharide chains. ${ }^{12}$ At present, 12 genes have been described, shown in table $1 . .^{13}$ Secreted and membrane associated forms have been found based on their function as extracellular viscous secretions or viscoelastic polymer gels or location as membrane anchored molecules in the glycocalyx. ${ }^{34}$ Two clusters have been reported, the secretory mucin genes MUC2, MUC5AC, MUC5B, and MUC6 on chromosome 11p15.5, and MUC3, MUC11, and MUC12 on chromosome 7q22. ${ }^{3}$

Histochemical techniques for mucin detection rely on the ability to detect carbohydrate or negative charge and were widely used for classification of changes in disease. ${ }^{56}$ The use of lectins and anticarbohydrate antibodies has greatly improved the specific detection of mucins histochemically and biochemically. ${ }^{5}$ A group of mucin oligosaccharide antigens, including $\mathrm{Tn}$, sialyl-Tn, $\mathrm{T}$, Lewis $^{\mathrm{x}}$ and Lewis ${ }^{\mathrm{y}}$, sialyl and sulpho-Lewis ${ }^{\mathrm{x}}$ and -Lewis ${ }^{\mathrm{a}}$, and the blood group $\mathrm{ABH}$ antigens, have been identified and which arise from disease related pathways. ${ }^{2}$ These carbohydrate antigens appear in relation to disease status, progression, diagnosis, and prognosis but are not limited to the mucins alone and occur on other cellular glycoproteins and glycolipids. Therefore, caution is needed in the interpretation of results in histological analyses where no direct identification of mucin related material is made.

This review focuses on the role of mucins in gastrointestinal disease in the light of the dramatic improvements in specific detection of mucin gene products and sets this against the larger background literature with less informative methods.

\section{Intestinal metaplasia, gastric ulcer, and \\ Helicobacter pylori infection}

Mucins are implicated in the aetiology and may assist in the diagnosis of gastric intestinal metaplasia (IM) associated with gastric ulceration, Helicobacter pylori infection, and the risk of gastric cancer. The histochemical detection of mucins is used for classification into complete (type I), incomplete without sulphomucins (type II), and incomplete with sulphomucins (type III). ${ }^{5}$ The histochemical profiles of type I IM are similar to those in diffuse gastric cancers, and type III IM is similar to "intestinal" cancers with sulphomucins predominating over sialomucins. A progression from type I to type III IM was proposed during the development of gastric cancer. ${ }^{56}$ However, this relationship is not always found. Mucins with $O$-acetylated sialic acids ( $O$-acetylsialomucins) are not seen in type III IM or tumours but are observed in complete or type I IM. ${ }^{5}{ }^{6}$ However, recent data showing reactivity in types I and III IM suggest that $O$-acetylated sialomucins are much more prevalent in gastric IM and carcinoma than previously recognised. ${ }^{7}$ The truncated mucin oligosaccharides $\mathrm{Tn}$, sialyl-Tn, $\mathrm{T}$, and sialyl- $\mathrm{T}$ have been examined and show that all IM mucosae are positive for sialyl-Tn while only Tn is present in control cases. ${ }^{8}$

Normal stomach mucosa is characterised by expression of MUC1, MUC5AC, and MUC6. High levels of MUC2 and MUC3 appear in IM. ${ }^{9}$ The complete form (type I) demonstrates only MUC2 in goblet cells. In contrast, incomplete forms (types II and III) exhibit MUC1 and MUC5AC in both goblet and absorptive cells, MUC2 in goblet cells only, and MUC6 in over $60 \%$ of cases. This represents two phenotypes, a small intestinal/colonic pattern and a typical gastric pattern with MUC2. MUC3 and MUC4 have not been examined. ${ }^{10}$

$H$ pylori infection is associated with the development of gastritis, ulcers, and possibly gastric malignancies. The organism first penetrates the gastric mucous layer and then binds to specific mucus or epithelial cell targets. $H$ pylori infection results in a reversible alteration of mucin glycosylation which favours attachment of the bacteria. ${ }^{11}$ Fucosylated blood group antigens and sialylated and sulphated oligosaccharides are implicated in $H$ pylor $i$ binding to the gastric mucins mediated by a variety of bacterial adhesins. ${ }^{12}$

Degradation of gastric mucus by $H$ pylori by proteases and sulphatases has been proposed ${ }^{13}$ and refuted. ${ }^{14}$ The action of urease generating ammonia increases $\mathrm{pH}$ which destabilises the mucous layer. ${ }^{14}{ }^{15}$ This action, however, is not sufficient to cause collapse of the mucous barrier and together with bacterial binding to mucus favours survival of $H$ pylori in the mucous layer. Adherence of $H$ pylori to the gastric epithelial cells results in more serious damage and is mediated by blood group related carbohydrate antigens, for example, $\mathrm{Le}^{\mathrm{a}}$, sialyl Le $\mathrm{L}^{\mathrm{a}}, \mathrm{Le}^{\mathrm{b}}$, type $1 \mathrm{H}$, and type $2 \mathrm{H}$ and in particular fucosylated blood group antigens associated with blood group $\mathrm{O}$ phenotype. This explains the higher prevalence of ulcerative disease in individuals with this blood group.

$H$ pylori positive patients exhibit an increase in MUC6 in surface mucous cells with a reduction in MUC5AC. Reversal of the normal gastric pattern is corrected on elimination of infection. ${ }^{16}$ The advantage of such a reversal

Abbreviations used in this paper: IM, intestinal metaplasia; UC, ulcerative colitis; CD, Crohn's disease; VNTR, variable number tandem repeat. 
Table 1 Mucin genes and their location in the human gastrointestinal tract

\begin{tabular}{|c|c|c|c|}
\hline MUC gene & Chromosome & Mucin type & Major expression in normal gastrointestinal tract \\
\hline MUC1 & $1 \mathrm{q} 21$ & Membrane & $\begin{array}{l}\text { Salivary glands: acini } \\
\text { Oesophagus: surface stratified squamous epithelium, submucosal gland ducts } \\
\text { Stomach-fundus: surface epithelium, glands; body and antrum: surface foveolar cells, mucous neck cells } \\
\text { Small intestine: goblet cells and enterocytes in surface/villi and deep/crypts } \\
\text { Colorectum: goblet cells and colonocytes in surface/villi and deep/crypts }\end{array}$ \\
\hline MUC2 & $11 \mathrm{p} 15.5$ & Secreted, gel forming & $\begin{array}{l}\text { Small intestine: goblet cells in surface/villi and deep/crypts } \\
\text { Colon: goblet cells in surface/villi and deep/crypts }\end{array}$ \\
\hline MUC3 & $7 \mathrm{q} 22$ & Membrane & $\begin{array}{l}\text { Salivary glands: submaxillary gland acini } \\
\text { Stomach-body and antrum: surface foveolar cells } \\
\text { Small intestine: goblet cells and enterocytes in surface/villi } \\
\text { Colorectum: goblet cells and colonocytes in surface/villi }\end{array}$ \\
\hline MUC4 & $3 q 29$ & Membrane & $\begin{array}{l}\text { Oesophagus: surface stratified squamous epithelium, submucosal gland ducts } \\
\text { Stomach-fundus: surface epithelium, glands; body and antrum: surface foveolar cells, mucous neck cells } \\
\text { Small intestine: goblet cells and enterocytes in surface/villi and deep/crypts } \\
\text { Colorectum: goblet cells and colonocytes in surface/villi and deep/crypts }\end{array}$ \\
\hline MUC5AC & $11 \mathrm{p} 15.5$ & Secreted, gel forming & Stomach-fundus: surface epithelium; body and antrum: surface foveolar cells \\
\hline MUC5B & $11 \mathrm{p} 15.5$ & Secreted, gel forming & $\begin{array}{l}\text { Salivary glands: acini } \\
\text { Oesophagus: submucosal gland acini and ducts } \\
\text { Stomach-fundus: surface epithelium, } \\
\text { Colorectum: goblet cells in deep/crypts }\end{array}$ \\
\hline MUC6 & $11 \mathrm{p} 15.5$ & Secreted, gel forming & $\begin{array}{l}\text { Stomach-fundus: glands; body and antrum: mucous neck cells } \\
\text { Small intestine: duodenal Brunner's gland acini }\end{array}$ \\
\hline MUC7 & $4 q 13-q 21$ & Secreted, non-gel forming & Salivary glands: acini \\
\hline MUC8 & $12 \mathrm{q} 24.3$ & Secreted, gel forming? & Not expressed \\
\hline MUC9 & $1 \mathrm{p} 13$. & Secreted, gel forming & Not expressed \\
\hline MUC11 & $7 \mathrm{q} 22$ & Secreted, gel forming? & $\begin{array}{l}\text { Small intestine } \\
\text { Colorectum }\end{array}$ \\
\hline MUC12 & $7 \mathrm{q} 22$ & Membrane & Colorectum \\
\hline
\end{tabular}

of expression is not known as neither of these gastric MUC gene products has been isolated in pure form.

\section{Inflammatory bowel disease}

ULCERATIVE COLITIS AND CROHN'S DISEASE

Ulcerative colitis (UC) and Crohn's disease (CD) are multifactorial disorders with an unclear aetiology. The mucous layer is clearly compromised in UC and a thinner mucous layer is present compared with that overlying the intestinal mucosa in the normal state or in $\mathrm{CD} .{ }^{17} \mathrm{UC}$ is confined to the colorectum and the reduction in mucus thickness has been linked with depletion of goblet cells in affected colorectal mucosa, therefore reducing the potential for mucin production. ${ }^{18}$

Histological analysis of mucins in UC shows increased sialomucin with some depletion of $\mathrm{O}$-acetyl sialic acids, reduced sulphomucins, and is linked to the degree of inflammation. ${ }^{5}{ }^{6}$ The loss of colonic mucin sulphation does not appear in CD. Reduction of $O$-acetylation is related to the severity of $\mathrm{UC}$ and $\mathrm{CD}$ while terminal ileal $O$-acetylation is increased in $\mathrm{CD} .{ }^{5}{ }^{6}$ However, the colorectal loss may be in the $10 \%$ range observed for the natural abundance of non-O-acetylators. ${ }^{19}$ Additional indications that $O$-acetylation is modified in UC have come from studies with saponification sensitive antimucin antibodies. ${ }^{20}$ Differential changes in binding were detected in the proximal and distal colon in UC.

A mucin subfraction, identified by ion exchange chromatography, is lost in UC but retained in $\mathrm{CD}^{21}$ and has also been interpreted as general mucin depletion. Further analysis of this subfraction has not been assessed using MUC gene technology.

Metabolic labelling and chemical analysis of isolated colonic mucins have shown that a reduction in MUC2 sulphation and fucosylation is associated with severe disease in European colitics. ${ }^{18} 22$ Correlation of MUC2 synthesis and sulphation with secretion has led to the proposal that although MUC2 sulphation is reduced, preferential secretion of sulphated MUC2 occurs in active disease maintaining a constant level of secreted sulphated MUC2. ${ }^{23}$ Modulation of mucin sulphation is clearly important as South Asian colitics show no reduction in sulphate detected by HID/AB histochemical staining and metabolic labelling. ${ }^{24}$ In CD patients there is no reduction in sulphation detected by histological methods and a slight reduction detected by metabolic labelling. ${ }^{25}$ These data suggest a difference in mucin sulphation between mild and severe UC and CD.

Sialylation is increased in UC in agreement with lectin binding studies suggesting that the grade of inflammation also plays a role in the glycosylation patterns seen in the mucins. ${ }^{26}$ Expression of sialyl-GalNAc (sialyl-Tn) antigen on mucins in the non-dysplastic colonic mucosa of longstanding UC patients identifies an increased cancer risk. ${ }^{27}$ South Asian colitics have different mucin sialylation compared with their European counterparts. ${ }^{28}$ South Asians in Britain have a high incidence of UC but a low incidence of UC associated colorectal carcinoma relative to European patients. No comparable studies with CD have been done.

Depletion of mucin sulphation and sialic acid $O$-acetylation are important factors affecting mucin degradation by the enteric bacterial flora. They have been linked with a reduced protective function of the mucous barrier in UC. ${ }^{19}$

MUC2 is the major secreted mucin gene in normal and UC colonic mucosa and levels of MUC2 mRNA are similar to controls in UC patients with active and quiescent disease. ${ }^{29}$ No alteration in the normal pattern of high MUC2 and MUC4 and low MUC1 and MUC3 occurs in European colitic patients with severe disease ${ }^{30} 31$ or in South Asian colitics. Susceptibility genes for inflammatory bowel disease include 7q22, the locus of MUC3, MUC11, and MUC12. ${ }^{3}$ Analysis of polymorphisms of variable number tandem repeats (VNTRs) within the intestinal MUC3 gene suggests that rare alleles of the MUC3 gene may confer genetic predisposition to UC. ${ }^{32}$

In CD, MUC1 is reduced only when healthy and involved ileal mucosa from the same patients are compared. However, comparison of healthy mucosa from CD patients with normal controls shows reductions in MUC3 and MUC4, both major expressed genes in ileum, and also of MUC5B, present in low levels in normal intestinal mucosa. ${ }^{33}$ No changes were found for MUC1 or MUC2 in healthy intestinal mucosa from CD patients. The decrease in expression of MUC3 and MUC4 in both healthy and involved ileal mucosa suggests a primary or very early mucosal defect of these genes in $\mathrm{CD} .{ }^{33}$ In 
colorectal mucosa from CD patients no changes in MUC2 or MUC3 mRNA were detected. ${ }^{31} 34$

In contrast with the mRNA results, a significant decrease in MUC2 precursor biosynthesis and total MUC2 levels occurs in UC patients with active inflammation while normal levels are detected during remission of inflammation. ${ }^{29}$ However, an increase in MUC2 reactivity using VNTR antibody detection has been reported in both UC and CD due to post-transcriptional abnormalities. ${ }^{34}$ In view of the differing reactivity of VNTR and non-VNTR anti-MUC2 antibodies (for example, see Aksoy and colleagues ${ }^{35}$ ), careful reassessment of these results is required. However, these studies show that colonic biosynthesis and total levels of MUC2 vary according to the activity of the disease and implicate a role for inflammation.

\section{Ileoanal pouch}

The characteristic differences in ileal and colonic mucin sulphation and $\mathrm{O}$-acetylation are a good indicator of the adaptation of ileoanal pouch mucosa and indicate that these changes are established within the first 6-9 months after pouch formation. ${ }^{36}$ Low levels of sulphated and $O$-acetylated sialylated mucins are present in normal ileum and in the new pouch mucosa, and this increases in $50-72 \%$ of established pouches to show a more typical colonic type pattern. ${ }^{37}$ The mucins synthesised by ileoanal pouches have increased sulphation relative to normal ileum. ${ }^{36}$ However, complete adaptation to a colonic mucosa is not seen, even in pouches established for over five years. Recent investigation of MUC gene expression in ileoanal pouches showed no changes in detectable MUC1-4 mRNA but significant reductions in immunodetectable MUC1 and MUC3 compared with ileal controls. $^{38}$

\section{Barrett's oesophagus and oesophageal adenocarcinoma}

Barrett's oesophagus may precede the development of oesophageal adenocarcinoma. In reflux oesophagitis replacement of squamous epithelium by columnar epithelium (Barrett's oesophagus) resembles either gastric or intestinal mucosa. ${ }^{39}$ Mucin histochemistry has been used to characterise the malignant progression and its value in cancer prediction. However, no clear consensus has formed supporting an increase in sulphomucin or loss of $\mathrm{O}$-acetylation. ${ }^{40}$ Incomplete metaplasia with sulphomucins and aberrant Le ${ }^{\mathrm{a}}$ in goblet and columnar cells is present in all patients with oesophageal adenocarcinoma. Further, Lewis $(\mathrm{a}+\mathrm{b}-)$, non-secretor, and blood group A phenotypes correlate with oesophageal adenocarcinoma, suggesting a genetic susceptibility. ${ }^{41}$ No biochemical studies have been carried out.

There is little detailed study of mucin gene expression in oesophageal cancer. Our own work has shown continuing progression of MUC gene changes from Barrett's oesophagus to oesophageal adenocarcinoma. The gastric metaplasia shows similar expression to normal gastric mucosa with high levels of MUC5AC superficially and MUC6 in the glands, low MUC1 and MUC4, and no MUC2. In contrast, intestinal type metaplasia is characterised by strong expression of MUC2 in goblet cells together with MUC5AC and MUC6 in glands, and MUC3 in the superficial epithelium. ${ }^{42}$ These patterns are similar to those reported in gastric IM. ${ }^{10}$ In dysplasia and neoplasia, downregulation of MUC2, MUC3, MUC5AC, and MUC6 occurs, while MUC1 and MUC4, membrane associated mucins, are more abundant.

\section{Gastric cancer}

Detection of mucin features in the classification systems used to grade gastric cancers, including the WHO classification, Lauren; intestinal and diffuse types, and Goseki, mucin poor (types I and III), and mucin rich (types II and IV).

The mucin oligosaccharides $\mathrm{Tn}$, sialyl-Tn, and $\mathrm{T}$ antigens are found in more than $90 \%$ of primary gastric adenocarcinomas. ${ }^{83}$ However, the association with cancer is not always clear, for example, antigen expression is related to cell type, with Tn predominantly in columnar cells and sialyl-Tn in goblet cells. ${ }^{44}$ Further, sialyl-Le ${ }^{\text {a }}$ shows a strong association with an unfavourable outcome if all gastric tumours are grouped, while sialyl-Tn, sialyl- Le ${ }^{a}$, and sialyl- $\mathrm{Le}^{\mathrm{x}}$ are linked with a worsening prognosis in the subgroup of diffuse gastric cancers. ${ }^{45}$ Sialyl-Tn is an excellent marker of small intestinal mucins and is indicative of small intestinal-type differentiation in two thirds of gastric cancers. ${ }^{46}$ It is a marker of gastric cancer progression suggesting that cancer associated mucins play a role in the malignant behaviour of these tumours. ${ }^{47}$ Lewis $(a+/ b-)$ and non-secretor phenotypes have a significant positive association with expression of sulphomucins in gastric cancer populations ${ }^{48}$ and sulpho-Le $\mathrm{e}^{\mathrm{a}}$ is found with high frequency in gastric cancers compared with normal gastric mucosa ${ }^{49}$ It is clear from these studies that the significance of these carbohydrate antigens in mucins remains to be explained. As already emphasised, they are not exclusive to mucins and are present in cell membranes and cytoplasm.

Patterns of MUC gene expression appear to be more promising as specific indicators of gastric cancer phenotypes. Immunohistological detection of MUC1 in gastric cancers correlates with gastric cancer development and progression, ${ }^{50}$ poor outcome, ${ }^{51}$ cell invasiveness, and poor prognosis. ${ }^{52}$ MUC2 is not normally found in the healthy gastric mucosa but is present in tumours where immunoreactivity relates best with the histological pattern but not with patient age or disease outcome. ${ }^{53}$ Detection in gastric carcinoma is prognostic for a favourable outcome..$^{51}$ However, a different anti-MUC2 VNTR antibody shows no significant difference between tumours according to their classification, stage, and lymph node status and has limited prognostic value,${ }^{54}$ underlining the importance of antibody design in relation to the expected population of mucins detected.

Immunoreactivity with an anti-MUC5AC VNTR peptide antibody shows positive binding in over $60 \%$ of gastric cancers with $>80 \%$ of diffuse carcinomas but only $59 \%$ of the intestinal type. Mixed phenotype cancers fitted this pattern with less reactivity in the intestinal regions. All early cancers are positive while advanced carcinomas lose reactivity suggesting that MUC5AC expression may be used as a marker of gastric differentiation. ${ }^{55}$ A pattern of strong surface expression and weak expression in deeper areas of advanced carcinomas reflects the normal pattern in gastric mucosa.

Improved assessment of mucin phenotypes in gastric cancer has come from analysis of groups of MUC genes. Combined evaluation of MUC1 and MUC2 mucin staining has been proposed as a clinically useful test to predict disease outcome. ${ }^{51}$ Characteristic patterns for MUC2, MUC3, MUC4, MUC5AC, and MUC6 are found in gastric cancers with increasing heterogeneity in advanced cancer stages. ${ }^{9}$ Two patterns relate to intestinal- or diffusetype gastric cancer. These are the gastric-type dominated by MUC5AC and MUC6, especially in early diffuse gastric cancer, and the intestinal-type with significant MUC2 expression against a background of MUC5AC and MUC6. Mixed phenotype tumours present intermediate patterns. Levels of the membrane mucins MUC1, MUC3, 
and MUC4 may provide additional refinement to this type of analysis.

Populations at high risk of gastric cancer have been identified on the basis of MUC1 and MUC6 polymorphism. Shorter alleles of these two genes identify genotypes at increased risk of gastric neoplasia. ${ }^{567}$

\section{Colorectal cancer}

Both qualitative and quantitative changes occur in the mucins produced in colorectal neoplasia. ${ }^{2}$ In adenocarcinomas these included reduction in total mucus output, ${ }^{6}$ reduction in sulphation, and sialic acid $O$-acetylation, but an increase in sialylated mucin. ${ }^{2}$ Mucinous carcinomas show a different phenotype with hypersecretion of mucin, no significant loss of sulphation but with changes in sialic acid content and $O$-acetylation. ${ }^{58}$ The oligosaccharide chains of mucins from colorectal cancers are shorter, resulting in new antigenicities. ${ }^{2}$ Most attention has focused on the truncated structures $\mathrm{Tn}, \mathrm{T}$, sialyl-Tn, the Lewis blood group antigens, and their sialylated and sulphated derivatives. $\mathrm{Tn}, \mathrm{T}$, and sialyl-Tn are expressed in over $90 \%$ of colorectal cancers and are absent in normal colonic mucosa. ${ }^{43} 59 \mathrm{~T}$ antigen is found in moderately and well differentiated colorectal adenocarcinomas, in contrast with Tn, common in poorly differentiated tumours. ${ }^{60}$ All three antigens are present in colorectal polyps and correlate with size, histological type, and level of dysplasia when found.

Modified forms of carbohydrate chains found in normal colorectal mucins include sialylated Lewis ${ }^{a}$ (Ca 19.9) and sialyl-Le ${ }^{\mathrm{x}}$. Sialyl-Lewis ${ }^{\mathrm{a}}$ is increased in most colorectal cancers, and in hyperplastic and adenomatous polyps, ${ }^{61}$ although its appearance is independent of location, differentiation, stage of disease, or prognosis in colorectal cancer. Sialic acid $\mathrm{O}$-acetylation is deleted early in the adenoma-carcinoma sequence ${ }^{62}$ and has been shown to mask the detection of both sialyl- $\operatorname{Tn}^{63}$ and sialyl-Le ${ }^{\mathrm{x} 64}$ in the normal colon, suggesting that the appearance of these antigens in neoplasia ${ }^{6065}$ may be due to loss of $O$-acetylation.

Sulphomucin depletion occurs in colorectal adenocarcinoma ${ }^{66}$ but not mucinous carcinoma. Sulpho$\mathrm{Le}^{\mathrm{a}}$ on colorectal mucins shows a progressive decrease from early to advanced adenocarcinomas. ${ }^{67}$ Improved detection of total sulphated epitopes in sulphomucins is required to evaluate this phenomenon.

Normal expression of the A, B, H, Le $e^{\mathrm{a}}$, and $\mathrm{Le}^{\mathrm{b}}$ blood group antigens is found in the fetal gut but is deleted in the normal distal colon after birth. A high proportion of colorectal cancers show abnormal re-expression at this site together with incompatible blood group antigen in colon cancers. More extensive reviews of the changes in glycosylation and their associated mechanisms occurring in colorectal cancers have been presented (see Kim and colleagues $^{2}$ ).

Levels of MUC1, 2, and $3 \mathrm{mRNA}$ are decreased in colorectal cancer and premalignant polyps but mucin peptide detected with antibodies against deglycosylated mucins showed increased reactivity. ${ }^{3168}$ These results may suggest abnormal apomucin processing, as fully glycosylated mucin is not detected by these antibodies. A dual nature for mucins in colorectal cancer based on MUC1 and MUC2 expression defines absorptive and goblet cell phenotypes, respectively. ${ }^{69}$

MUC gene expression in the adenoma-carcinoma sequence is characterised by switch on of MUC5AC and MUC6. These genes are detected at the $\mathrm{mRNA}^{70-72}$ and peptide levels. ${ }^{71-73}$ In addition, upregulation of MUC2 mRNA occurs in adenomas with increasing villosity and is reduced in adenocarcinomas, ${ }^{70}$ although this was not found by $\mathrm{Ho}$ and colleagues. ${ }^{71}$ Increased MUC2 peptide is detected with increasing villous architecture and polyp size. ${ }^{71}$ In contrast, flat and polypoid tubular adenomas show reduced MUC2 and MUC4 mucin in high grade atypia using VNTR antibodies. ${ }^{73} 74$

These changes indicate the appearance of the gastrictype MUC gene phenotype against a background of colonic mucin (MUC2, MUC3, and MUC4). The significance of increased anti-VNTR antibody reactivity may be related to premature apomucin ${ }^{71}$ or abnormal processing and requires further study. MUC2 gene suppression in colorectal cancer is linked with methylation of the promoter region and may represent a major regulatory mechanism. ${ }^{75}$

Mucinous carcinomas represent a separate group of colorectal cancers characterised by over expression of MUC2, a common genetic lesion in these tumours. ${ }^{58}$

Increased membrane mucin MUC1 levels correlate with progression of colorectal cancer and metastasis ${ }^{76}$ and location of MUC1 in the deep invasive region of tumours is prognostic. ${ }^{77}$ Detection of MUC1 in serum is a predictor of colorectal and other cancers. ${ }^{78}$ MUC1 expressed in colorectal cancer shows abnormal glycosylation, ${ }^{79}$ in particular increased levels of sialyl-Le ${ }^{\mathrm{x}}{ }^{80-82}$ The high expression of MUC1 and increased exposure of the tandem repeat sequence through aberrant glycosylation has led to the development of anti-MUC1 vaccine cancer therapies. ${ }^{83}$

Two new MUC genes, MUC11 and 12 (table 1), with major colorectal expression, both downregulated in colorectal cancer, have been identified recently. ${ }^{3}$ The presence of epidermal growth factor-like domains in MUC12 shows sequence homology with epidermal growth factor receptor-binding growth factors and with similar domains on MUC3 and MUC4. It has been proposed that these regions are important for the function of these mucins as growth regulators in the colon and their downregulation in colorectal cancer an important stage in colorectal carcinogenesis. ${ }^{3}$

\section{Paediatric disease}

Most studies of mucosal paediatric disease have been concerned with Hirschsprung's disease and associated enterocolitis. The production of a viable mucous barrier in the colorectal mucosa in patients with Hirschsprung's disease has been questioned due to the increased susceptibility of these patients to enterocolitis. Histological examination of the mucus present in the mucosa from these patients appeared to be normal, the colonic mucins being primarily $O$-acetylated and sulphated. ${ }^{84}$ Mucus turnover determined by metabolic labelling showed a reduction in both Hirschsprung's disease (aganglionic) colon segments and in adjacent ganglionic bowel, which is retained at the definitive pull through operation. ${ }^{85}$ MUC gene expression was similar in patients and controls. MUC2 and 4 were strongly expressed, MUC1, 3, and 5B had moderate to weak expression, and MUC $5 \mathrm{AB}, 6,7$, and 8 had baseline expression. Thus expression of mucin genes and the quality of mucins is similar to normal controls. ${ }^{84}$

The abnormal mucus turnover will result in a weakening of the protective function of the mucous barrier and may be an aetiological factor in the pathogenesis of enterocolitis of Hirschsprung's disease. In addition, demonstration of the same defect in adjacent ganglionic bowel used to repair the lesion suggests that a reassessment of the surgical procedure may be required and the extent of the modified mucus turnover in ganglionic bowel for these patients should be assessed. A mechanism for reduced turnover in these patients remains to be determined.

A significant alteration in mucins with an increase in neutral mucins and a decrease in acidic-sulphomucins occurs in Hirschsprung's disease associated enterocolitis ${ }^{86}$ 
and although mucus depletion is strongly implicated here and in necrotising enterocolitis, ${ }^{87}$ there are few data indicating the precise nature and cause.

\section{Conclusions and summary}

Recent advances in the detection of the growing family of MUC genes using nucleic acid probes and both VNTR and non-VNTR antibodies are making a significant impact on the ability to detect patterns of expression in gastrointestinal disease. This progress suggests that it may be possible to identify disease phenotypes more readily than with previous glycosylation based detection. The clinical impact of these developments will be in improved diagnosis and prognosis in disease screening and expansion of the current antimucin vaccine trials with MUC1 and sialyl-Tn to other mucin genes implicated in gastrointestinal disease.

Sharing of carbohydrate antigens with non-mucin glycoconjugates remains a significant limitation in this respect. The secretory and membrane associated nature of the MUC gene products requires clear functional significance, and regulation of these genes is only starting to be investigated. Future development will be aimed at identification of MUC gene product glycosylation in diseases related to the protective functions at the mucosal surface, their role in cell and matrix adhesion, and metastasis.

A P CORFIELD N MYERSCOUGH Mucin Research Group, Dorothy Crowfoot Hodgkin Labs, Division of Medicine, Bristol Royal Infirmary, Bristol BS2 8HW, UK

R LONGMAN

P SYLVESTER

Division of Surgery, Bristol Royal Infirmary, Bristol BS2 8HW, UK

$S$ ARUL

Paediatric Surgery, Bristol Royal Hospital for Sick Children,

Bristol BS2 8Bf, UK

M PIGNATELLI

Department of Pathology and Microbiology, Bristol Royal Infirmary, Bristol BS2 8HW, UK

Correspondence to: A P Corfield. Email: Tony.Corfield@bristol.ac.uk

The work reported in this review was supported by grants from the Wellcome Trust (grant 051586/Z/97); RL was supported by a training fellowship from the Royal College of Surgeons of England and a South and West Research Studentship.

1 Gendler SJ, Spicer AP. Epithelial mucin genes. Annu Rev Physiol 1995;57:607-34.

2 Kim YS, Gum JJ, Brockhausen I. Mucin glycoproteins in neoplasia. Glycoconj $\mathcal{F}$ 1996;13:693-707.

3 Williams SJ, McGuckin MA, Gotley DC, et al. Two novel mucin genes down-regulated in colorectal cancer identified by differential display. Cancer Res 1999;59:4083-9.

4 van Klinken BJW, Dekker J, Buller HA, et al. Mucin gene structure and expression: Protection vs. adhesion. Am F Physiol 1995;269:G613-27.

5 Filipe IM, Ramachandra S. The histochemistry of intestinal mucins; changes in disease. In: Whitehead R, ed. Gastrointestinal and oesophageal changes in disease. In: Whitehead R, ed. Gastrointestinal and oesophag

pathology, 2nd edn. Edinburgh: Churchill Livingstone, 1995:73-95.
6 Jass JR, Roberton AM. Colorectal mucin histochemistry in health and Jass JR, Roberton AM. Colorectal mucin histochen
disease: A critical review. Pathol Int 1994;44:487-504.

7 Mullen PJ, Carr N, Milton JD, et al. Immunohistochemical detection of $\mathrm{O}$-acetylated sialomucins in intestinal metaplasia and carcinoma of the stomach. Histopathology 1995;27:161-7

8 David L, Nesland JM, Clausen H, et al. Simple mucin-type carbohydrate antigens ( $\mathrm{Tn}$, sialosyl-Tn and $\mathrm{T}$ ) in gastric mucosa, carcinomas and metastases. APMIS Suppl 1992;27:162-72.

9 Ho SB, Shekels LL, Toribara NW, et al. Mucin gene expression in normal, preneoplastic, and neoplastic human gastric epithelium. Cancer Res 1995;55:2681-90.

10 Reis CA, David L, Correa P, et al. Intestinal metaplasia of human stomach displays distinct patterns of mucin (MUC1, MUC2, MUC5AC, and MUC6) expression. Cancer Res 1999;59:1003-7.

11 Ota $\mathrm{H}$, Nakayama J, Momose $\mathrm{M}$, et al. Helicobacter pylori infection produces reversible glycosylation changes to gastric mucins. Virchows Arch 1998;433:419-26.

12 Miller-Podraza H, Bergström J, Milh MA, et al. Recognition of glycoconjugates by Helicobacter pylori. Comparison of two sialic acid-dependent specificities based on haemagglutination and binding to human erythrocyte glycoconjugates. Glycoconj f 1997;14:467-71.
13 Slomiany BL, Slomiany A. Mechanism of Helicobacter pylori pathogenesis: focus on mucus. 7 Clin Gastroenterol 1992;14(suppl. 1):S114-21.

14 Sidebotham RL, Batten JJ, Karim QN, et al. Breakdown of gastric mucus in presence of Helicobacter pylori. $\mathcal{F}$ Clin Pathol 1991;44:52-7.

15 Newton JL, Jordan N, Oliver L, et al. Helicobacter pylori in vivo causes structural changes in the adherent gastric mucus layer but barrier thickness is not compromised. Gut 1998;43:470-5.

16 Byrd JC, Yan P, Sternberg L, et al. Aberrant expression of gland-type gastric mucin in the surface epithelium of Helicobacter pylori-infected patients. Gastroenterology 1997;113:455-64.

17 Pullan RD, Thomas GAO, Rhodes M, et al. Thickness of adherent mucus on colonic mucosa in humans and its relevance to colitis. Gut 1994:35:353-9.

18 McCormick DA, Horton LWL, Mee AS. Mucin depletion in inflammatory bowel disease. ${ }^{f}$ Clin Pathol 1990;43:143-6.

19 Roberton AM, Corfield AP. Mucin degradation and its significance in inflammatory conditions of the gastrointestinal tract. In: Tannock GW, ed. Medical importance of the normal microflora. Dordrecht: Kluwer Academic Mudical importance of the

20 Smithson JE, Campbell A, Andrews JM, et al. Altered expression of mucins through the colon in ulcerative colitis. Gut 1997;40:234-40.

21 Smith AC, Podolsky DK. Biosynthesis and secretion of human colonic mucin glycoproteins. $\mathcal{F}$ Clin Invest 1987;80:300-7

22 Corfield AP, Myerscough N, Bradfield N, et al. Colonic mucins in ulcerative colitis: Evidence for loss of sulphation. Glycoconj $\mathcal{F}$ 1996;13:809-22.

23 Van Klinken BJ, Van Der Wal JW, Einerhand AW, et al. Sulphation and secretion of the predominant secretory human colonic mucin MUC2 in ulcerative colitis. Gut 1999;44:387-93.

24 Probert CSJ, Warren BF, Perry T, et al. South Asian and European colitics show characteristic differences in colonic mucus glycoprotein type and turnover. Potential identification of a lower risk group for severe disease and cancer. Gut 1995;36:696-702.

25 Raouf AH, Tsai HH, Parker N, et al. Sulphation of colonic and rectal mucin in inflammatory bowel disease: reduced sulphation of rectal mucus in ulcerative colitis. Clin Sci 1992;83:623-6.

26 McMahon RTF, Jomes CIP, Dutt S, et al. Altered oligosaccharide expression in ulcerative colitis with increasing grades of inflammation. Glycosylation Dis 1994:1:235-45.

27 Itzkowitz SH, Young E, Dubois D, et al. Sialosyl-Tn is prevalent and precedes dysplasia in ulcerative colitis: A retrospective case-control study. Gastroenterology 1996;110:694-704.

28 McMahon RF, Warren BF, Jones CJ, et al. South Asians with ulcerative colitis exhibit altered lectin binding compared with matched European cases. Histochem f 1997;29:469-77.

29 Tytgat KMAJ, Van der Wal T-W, Einerhand AWC, et al. Quantitative analysis of MUC2 synthesis in ulcerative colitis. Biochem Biophys Res Commun 1996;224:397-405.

30 Myerscough N, Warren BF, Gough M, et al. Expression of mucin genes in ulcerative colitis. Biochem Soc Trans 1995;23:536S.

31 Weiss AA, Babyatsky MW, Ogata S, et al. Expression of MUC2 and MUC3 mRNA in human normal, malignant, and inflammatory intestinal tissues. $\mathcal{F}$ Histochem Cytochem 1996;44:1161-6.

32 Kyo K, Parkes M, Takei Y, et al. Association of ulcerative colitis with rare VNTR alleles of the human intestinal mucin gene, MUC3. Hum Mol Genet 1999;8:307-11.

33 Buisine MP, Desreumaux P, Debailleul V, et al. Abnormalities in mucin gene expression in Crohn's disease. Inflamm Bowel Dis 1999;5:24-32.

34 Hanski C, Born M, Foss HD, et al. Defective post-transcriptional processing of MUC2 mucin in ulcerative colitis and in Crohn's disease increases detectability of the MUC2 protein core. F Pathol 1999;188:304-11.

35 Aksoy N, Thornton DJ, Corfield A, et al. A study of the intracellular and secreted forms of the MUC2 mucin from the PC/AA intestinal cell line. Glycobiology 1999;9:739-46.

36 Corfield AP, Warren BF, Bartolo DCC, et al. Mucin changes in ileoanal pouches monitored by metabolic labelling and histochemistry. $\mathrm{Br}$ F Surg 1992;79:1209-12.

37 Shepherd NA, Healey CJ, Warren BF, et al. Distribution of mucosal pathology and an assessment of colonic phenotypic change in the pelvic ileal reservoir. Gut 1993;34:101-5.

38 Sylvester PA, Walsh MD, Myerscough N, et al. Alteration in mucin gene expression occurs as the mucosa of the ileoanal reservoir adapts. Gut 1998; 42(suppl 1):A91.

39 Jass JR. Mucin histochemistry of the columnar epithelium of the oesophagus: a retrospective study. F Clin Pathol 1981;34:866-70.

40 Lapertosa G, Baracchini P, Fulcheri E, et al. Mucin histochemical analysis in the interpretation of Barrett's esophagus: Results of a multicenter study. Am $\mathcal{F}$ Clin Pathol 1992;98:61-6.

41 Torrado J, Ruiz B, Garay J, et al. Blood-group phenotypes, sulfomucins, and Helicobacter pylori in Barrett's esophagus. Am F Surg Pathol 1997;21 $1023-9$.

42 Arul GS, Myerscough N, Moorghen M, et al. The expression of mucin genes in Barrett's oesophagus. Biochem Soc Trans 1999;27:A41.

43 Springer GF. Immunoreactive $\mathrm{T}$ and $\mathrm{Tn}$ epitopes in cancer diagnosis, prognosis, and immunotherapy. $\mathcal{F} \mathrm{Mol} \mathrm{Med} \mathrm{1997;75:594-602.}$

44 Carneiro F, Santos L, David L, et al. T (Thomsen-Friedenreich) antigen and other simple mucin-type carbohydrate antigens in precursor lesions of gastric carcinoma. Histopathology 1994;24:105-13.

45 Baldus SE, Zirbes TK, Monig SP, et al. Histopathological subtypes and prognosis of gastric cancer are correlated with the expression of mucin-associated sialylated antigens: sialosyl-Lewis(a), sialosyl-Lewis(x) and sialosyl-Tn. Tumour Biol 1998;19:445-53.

46 Iwata H, Itzkowitz SH, Werther JL, et al. Expression of sialosyl-Tn in intestinal type cancer cells of human gastric cancers. Acta Pathol fpn 1993;43:646-53.

47 Werther JL, Tatematsu M, Klein R, et al. Sialosyl-Tn as a marker of gastric cancer progression: An international study. Int f Cancer 1996;69:193-9.

48 Torrado J, Ruiz B, Garay J, et al. Lewis, secretor, and ABO phenotypes, and sulfomucin expression in gastric intestinal metaplasia. Cancer Epidemiol Biomarkers Prev 1997;6:287-9.

49 Ohe Y, Hinoda Y, Irimura T, et al. Expression of sulfated carbohydrate chains detected by monoclonal antibody $91.9 \mathrm{H}$ in human gastric cancer tissues. Fpn f Cancer Res 1994;85:400-8.

50 Reis CA, David L, Seixas M, et al. Expression of fully and underglycosylated forms of MUC1 mucin in gastric carcinoma. Int $\mathcal{F}$ Cancer 1998;79:402-10 
51 Utsunomiya T, Yonezawa S, Sakamoto H, et al. Expression of MUC1 and MUC2 mucins in gastric carcinomas: its relationship with the prognosis of the patients. Clin Cancer Res 1998;4:2605-14.

52 Nakagawa K, Akagi J, Takai E, et al. Prognostic values of MUC-1 molecule expressing cytokine receptor-like epitope and DF3 in patients with gastric carcinoma. Int f Oncol 1999;14:425-35.

53 Sakamoto H, Yonezawa S, Utsunomiya T, et al. Mucin antigen expression in gastric carcinomas of young and old adults. Hum Pathol 1997;28:1056-65.

54 Filipe MI, Linehan JM, Durrant LG, et al. Expression of a peptide epitope of the colonic mucin MUC2 in precursor lesions to gastric carcinoma. Eur $f$ Cancer Prev 1996;5:287-95.

55 Reis CA, David L, Nielsen PA, et al. Immunohistochemical study of MUC5AC expression in human gastric carcinomas using a novel monoclonal antibody. Int f Cancer 1997;74:112-21.

56 Carvalho F, Seruca R, David L, et al. MUC1 gene polymorphism and gastric cancer-an epidemiological study. Glycoconj $\mathcal{F}$ 1997;14:107-11.

57 Garcia E, Carvalho F, Amorim A, et al. MUC6 gene polymorphism in healthy individuals and in gastric cancer patients from northern Portugal. hancer Epidemiol Biomarkers Prev 1997;6:1071-4

58 Hanski C, Hofmeier M, Schmitt-Graff A, et al. Overexpression or ectopic expression of MUC2 is the common property of mucinous carcinomas of expression of MUC2 is the common property of mucinous carcin
the colon, pancreas, breast, and ovary. $\mathcal{F}$ Pathol 1997;182:385-91.

59 Ogata S, Koganty R, Reddish M, et al. Different modes of sialyl-Tn expression during malignant transformation of human colonic mucosa. Glycocon f 1998;15:29-35.

60 Itzkowitz SH, Yuan M, Montgomery CK, et al. Expression of Tn, sialosyl-Tn and $\mathrm{T}$ antigens in human colon cancer. Cancer Res 1989;49:197-204.

61 Itzkowitz SH, Yuan M, Fukushi Y, et al. Immunohistochemical comparison of Le ${ }^{\mathrm{a}}$, monosialosyl Le ${ }^{\mathrm{a}}$ (CA 19.9), and disialosyl $\mathrm{Le}^{\mathrm{a}}$ antigens in human colorectal and pancreatic tissues. Cancer Res 1988;48:3834-42.

62 Corfield AP, Myerscough N, Warren BF, et al. Reduction of sialic acid $\mathrm{O}$-acetylation in human colonic mucins in the adenoma-carcinoma sequence. Glycoconj $\mathcal{F}$ 1999;16:307-17.

63 Jass JR, Allison LJ, Edgar SG. Distribution of sialosyl-Tn and Tn antigens within normal and malignant colorectal epithelium. F Pathol 1995;176:143-9.

64 Mann B, Klussmann E, Vandamme Feldhaus V, et al. Low acetylation of sialyl-Le (x) contributes to its overexpression in colon carcinoma metassialyl-Le(x) contributes to its over
tases. Int $\mathcal{f}$ Cancer 1997;72:258-64.

65 Hanski C, Bornhoeft G, Topf N, et al. Detection of a mucin marker for the adenoma-carcinoma sequence in human colonic mucosa by monoclonal adenoma-carcinoma sequence in human colo

66 Yamori T, Kimura H, Stewart K, et al. Differential production of high molecular weight sulfated glycoproteins in normal colonic mucosa, primary carcinoma, and metastasis. Cancer Res 1987;47:2741-7.

67 Matsushita Y, Yamamoto N, Shirahama H, et al. Expression of sulfomucins in normal mucosae, colorectal adenocarcinomas, and metastases. $\mathcal{F p n} \mathcal{F}$ Cancer Res 1995;86:1060-7.

68 Ogata S, Uehara $\mathrm{H}$, Chen A, et al. Mucin gene expression in colonic tissues and cell lines. Cancer Res 1992;52:5971-8.

69 Ajioka Y, Xing PX, Hinoda Y, et al. Correlative histochemical study providing evidence for the dual nature of human colorectal cancer mucin. Histochem f 1997;29:143-52.

70 Buisine M-P, Janin A, Mauroury V, et al. Abberant expression of a human mucin gene (MUC5AC) in rectosigmoid villous adenoma. Gastroenterology 1996;110:84-91.
71 Ho SB, Ewing SL, Montgomery CK, et al. Altered mucin core peptide immunoreactivity in the colon polyp-carcinoma sequence. Oncol Res 1996; 8:53-61.

72 Bartman AE, Sanderson SJ, Ewing SL, et al. Aberrant expression of MUC5AC and MUC6 gastric mucin genes in colorectal polyps. Int 7 Cancer 1999;80:210-18.

73 Biemer-Huttmann AE, Walsh MD, McGuckin MA, et al. Immunohistochemical staining patterns of MUC1, MUC2, MUC4, and MUC5AC mucins in hyperplastic polyps, serrated adenomas, and traditional mucins in hyperplastic polyps, serrated adenomas, and tradition
adenomas of the colorectum. F Histochem Cytochem 1999;47:1039-48.

74 Ajioka Y, Watanabe H, Jass JR. MUC1 and MUC2 mucins in flat and polypoid colorectal adenomas. F Clin Pathol 1997;50:417-21.

75 Hanski C, Riede E, Gratchev A, et al. MUC2 gene supression in human colorectal carcinomas and their metastases: In vitro evidence of the modulatory role of DNA methylation. Lab Invest 1997;77:685-95.

76 Nakamori SDMO, Cleary KR, Shirotani K, et al. MUC1 mucin expression as a marker of progression and metastasis of human colorectal carcinoma. Gastroenterology 1994;106:353-61

77 Hiraga Y, Tanaka S, Haruma K, et al. Immunoreactive MUC1 expression at the deepest invasive portion correlates with prognosis of colorectal cancer. Oncology 1998;55:307-19.

78 MacLean GD, Reddish MA, Longenecker BM. Prognostic significance of preimmunotherapy serum CA27.29 (MUC-1) mucin level after active specific immunotherapy of metastatic adenocarcinoma patients. F Immunother 1997;20:70-8

79 Medina M, Velez D, Asenjo JA, et al. Human colon adenocarcinomas express a MUC1-associated novel carbohydrate epitope on core mucin glycans defined by a monoclonal antibody (A10) raised against murine Ehrlich tumor cells. Cancer Res 1999;59:1061-70.

80 Burdick MD, Harris A, Reid CJ, et al. Oligosaccharides expressed on MUC1 produced by pancreatic and colonic tumour cell lines. 7 Biol Chem 1997;272:24198-202.

81 Hanski C, Hanski M-L, Zimmer T, et al. Characterization of the major sialyl-Le $\mathrm{L}^{\mathrm{x}}$-positive mucins present in colon, colon carcinoma, and sera of patients with colorectal cancer. Cancer Res 1995;55:928-33.

82 Baldus SE, Hanisch FG, Kotlarek GM, et al. Coexpression of MUC1 mucin peptide core and the Thomsen-Friedenreich antigen in colorectal neoplasms. Cancer 1998;82:1019-27.

83 Agrawal B, Gendler SJ, Longenecker BM. The biological role of mucins in cellular interactions and immune regulation: prospects for cancer immunotherapy. Mol Med Today 1998;4:397-403.

84 Aslam A, Spicer RD, Corfield AP. Histochemical and genetic analysis of colonic mucin glycoproteins in Hirschsprung's disease. 7 Pediatr Surg 1999;34:330-3.

85 Aslam A, Spicer RD, Corfield AP. Children with Hirschsprung disease have an abnormal colonic mucosal defensive barrier independent of the bowel innervation status. F Pediatr Surg 1997;32:1206-10.

86 Teitelbaum DH, Caniano DA, Qualman SJ. The pathophysiology of Hirschsprung's-associated enterocolitis: importance of histologic correlates. F Pediatr Surg 1989;24:1271-7.

87 Israel EJ. Neonatal necrotizing enterocolitis, a disease of the immature intestinal mucosal barrier. Acta Paediatr 1994;(suppl. 396):27-32. 